\title{
"Practical Work as It Says Practical is Something Students do by Themselves..."
}

\author{
Awelani V Mudau \\ Department of Science and Technology Education, University of South Africa, South Africa \\ Ramodungoane Tabane \\ Department of Psychology of Education, University of South Africa, South Africa \\ Tabanrj@unisa.ac.za
}

\section{Doi:10.5901/mjss.2014.v5n3p446}

\section{Abstract}

The aim of the study was to investigate teachers' classroom practices by focusing on how their ideas and views shape how they conduct practical work in a science classroom. Two physical science teachers were involved in the study. The study showed that one teacher had ideas about the nature and purpose of practical work within the framework of the investigation movement. The second teacher had ideas about the nature and purpose of practical work within the process and investigation movements respectively. However, both teachers conducted practical work tasks within the explanation model. Hence teachers' ideas of practical work do not necessarily shape how they conduct practical work. Possible reasons for the teachers conducting practical work tasks within the framework in ways different to those suggested by their ideas and their implications are discussed.

Keywords: practical work, procedural understanding, explanation model

\section{Introduction}

The paper reports on the study conducted in South Africa in the Gauteng province. The new curriculum (National Curriculum Statement, also known as NCS and most recently as CAPS) in South Africa brought with it reinforced emphasis on the importance of practical work. Micro kits for practical work equipments were delivered to most schools by the Department of Basic Education (DBE) and DBE assessment policies now also assert that there should be evidence of practical work in the form of reports in the students' portfolios. Snapshots of some of the cluster visited revealed that practical work reports are indeed being submitted as part of the portfolio work for continuous assessment (CASS). However, when some teachers were asked about the importance of conducting pratical work, tangible reasons were not forthcoming. As such we became interested in finding out their ideas about practical work as well as how these ideas shaped the manner in which they conducted lessons in the classroom. Studies by Perkins-Gough (2007), Ottander and Grelsson (2006), Stoffels (2005) and Hodson (1990) show that teacher practice does have an impact on how practical work is conducted. In this study, therefore, we investigated teachers' ideas on practical work and how those ideas relate to their actual practice. The following research questions guided the study: What are teachers' ideas about the nature and purpose of practical work? How do teachers' ideas about the nature of practical work and its purpose shape how they conduct practical work?

\section{Literature Review}

The Department of Education (2007:10) indicates that "practical investigations and experiments should assess all learning outcomes with the focus on the practical work aspects and the process skills required for scientific inquiry and problem solving". Hence, within the NCS curriculum, practical work caters for procedural understanding and substantive understanding with the goal of developing problem-solving skills.

The study by Pekmez, Johnson and Gott (2005) which investigated the thinking of teachers about practical work in the context of the English national curriculum for science in England identified three movements that have influenced practical work in the UK and the USA. The movements are summarised in table 1. 
Table 1: Characteristics of movements influencing practical work

\begin{tabular}{|c|c|c|c|}
\hline \multicolumn{4}{|c|}{ Movement } \\
\hline \multirow{4}{*}{$\begin{array}{c}\text { Main } \\
\text { Characteristics }\end{array}$} & Discovery learning & The process approach & Investigations \\
\hline & $\begin{array}{l}\text { 1.Learners expected to discover } \\
\text { things for themselves }\end{array}$ & $\begin{array}{l}\text { 1. Motivates the identification } \\
\text { of what scientists do and } \\
\text { argue that this is what must } \\
\text { be taught }\end{array}$ & $\begin{array}{l}\text { 1. The approach was confounded on the } \\
\text { focus that pupils should be thinking about } \\
\text { what they are doing rather than simply } \\
\text { applying the method practised }\end{array}$ \\
\hline & $\begin{array}{l}\text { 2. Practical work seen as the } \\
\text { means in which pupils will develop } \\
\text { their thinking }\end{array}$ & $\begin{array}{l}\text { 2. Content not a priority but } \\
\text { the scientific method }\end{array}$ & $\begin{array}{l}\text { 2. The approach develops procedural and } \\
\text { substantive understanding }\end{array}$ \\
\hline & $\begin{array}{l}\text { 3. This is a teaching method which } \\
\text { leaves things open for discovery } \\
\text { but also offers an opportunity for } \\
\text { not discovering them }\end{array}$ & $\begin{array}{l}\text { 3. This is a teaching method } \\
\text { that focuses on skill and } \\
\text { neglects content }\end{array}$ & $\begin{array}{l}\text { 3. The ultimate aim is to develop problem- } \\
\text { solving skills }\end{array}$ \\
\hline
\end{tabular}

From table 1, it is evident that the South African Department of Education's ideas about practical work can be aligned with the investigation movement. In analysing and explaining the thinking of teachers about practical work the following models used by Pekmez et al. (2005) were adopted.

The performance model (figure 1) is based on the investigation movement approach. The teacher has the intention of developing substantive understanding as well as procedural understanding. Hence practical work is used as an explanatory framework and for selection and organisation of routines (skills) for mental processing. The ultimate goal of this approach is to develop problem-solving skills among learners.

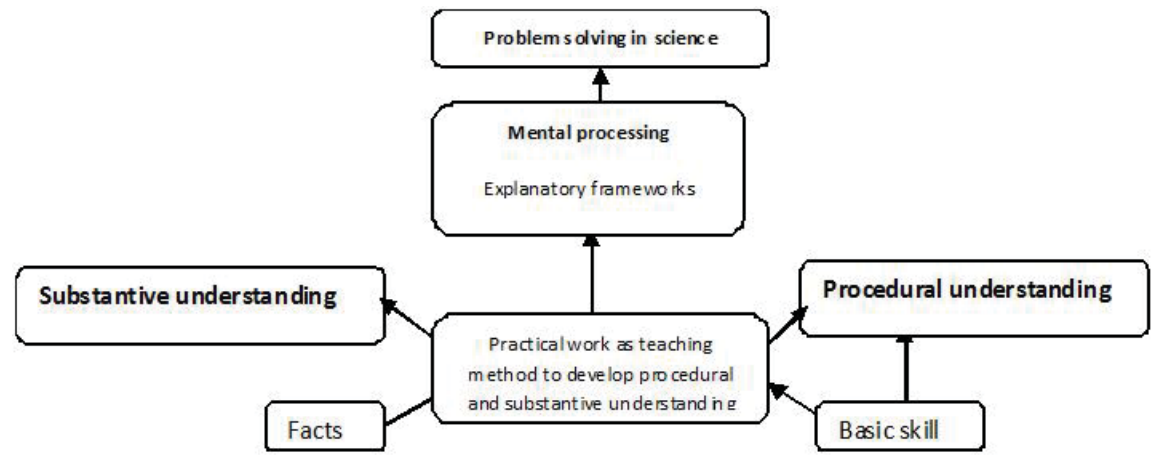

Figure 1: A performance model

The explanation model (figure 2) depicts practical work as a teaching method to support substantive understanding and laboratory work as just a teaching method towards this end (Pekmez et al., 2005). Practical work is used as an explanatory framework for the explanations in science.

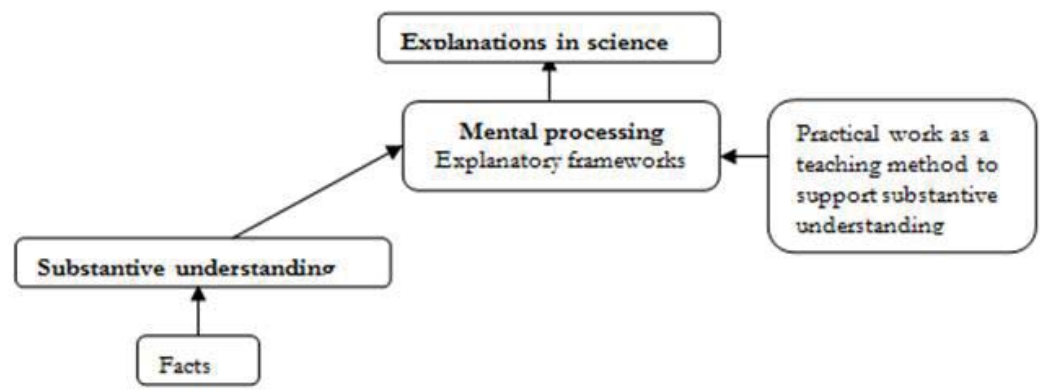

Figure 2: An explanations model 
The doing of science model (figure 3) uses practical work as a teaching method to support skills development. Pekmez et al. (2005) indicate that in this model teachers concentrate on the skills rather than the ideas to be understood. In this model a teacher thinks of practical work from the process approach movement.

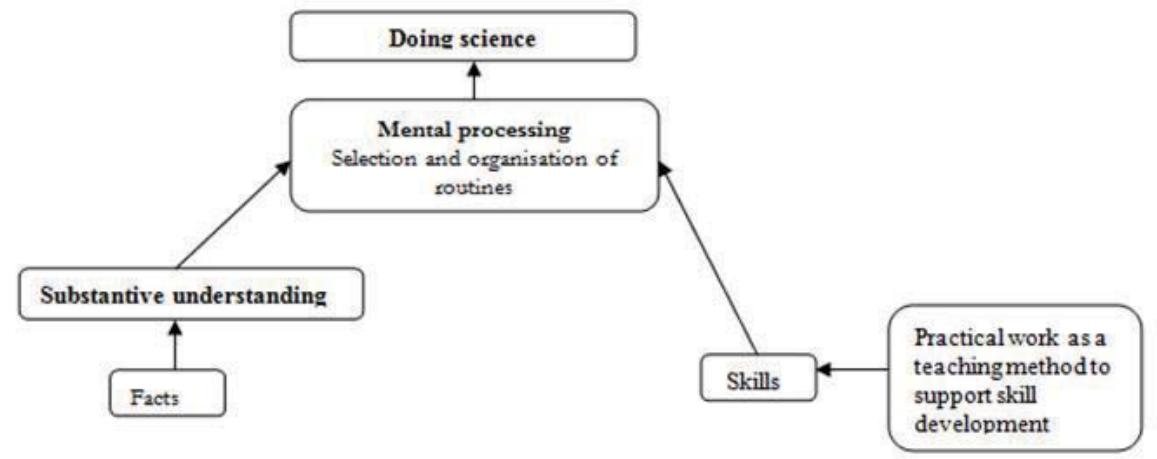

Figure 3: A doing model

In this study how teachers conducted practical work was analysed using the modified model on the process of developing and evaluating a laboratory work task by Millar, Le Maréchal and Tiberghien (2002). According to the model, teachers' objectives and the design features of tasks (what the students are intended to learn) are influenced by the teachers' views of science and learning (what practical work is, and its purpose) and the practical and institutional context (e.g. availability of apparatus, class size and the requirements of the curriculum).

\section{Research Methodology}

The study adopted a descriptive case study method. Hitchcock and Hughes (1995:321) indicate that "descriptive case studies have aimed at giving a narrative account of life as it is in a social situation". The choice was influenced by what can be done, what was practical, situational factors and interest. Semi-structured interviews and official documents were used to gather data for the study. Semi-structured interviews were used as they offered the opportunity to ask the question 'why' and we could also deviate from the prearranged text and wording of questions. Official documents in the form of practical work task reports and instruction sheets were used as they offered an opportunity to obtain data with little contact between myself and the teachers. Teachers chose the sample of practical work task reports and instruction sheets of what best represent what they wanted their learners to do, in my presence for authenticity (McMillan and Schumacher, 2006). Interviews and official documents were also used to check and compare what the teachers say they know and do with what they do in class. This was necessary to attain internal validity for the study so that it could be trustworthy and credible as the data from two different data collection strategies was triangulated.

The data was collected from three Grade 10 physical science teachers. One of the teachers was used to pilot the research procedures. To eliminate lack of confidence, training, apparatus and take into account teachers' background, teachers teaching at schools with a fairly well-equipped laboratory who were qualified to teach physical science, and with at least two years of experience at a particular school, were purposefully chosen. These factors were considered because Rogan and Grayson (2003) indicate that they do influence the implementation of new ideas.

Data was analysed and interpreted using the typology model. Hatch (2002:148) indicates that this is the method wherein data is interrogated and organised "... in ways that allow the researchers to see patterns, identify themes, discover relationships, develop explanations, make interpretations ...". The first research question (teacher's ideas of the nature of practical work and teacher's ideas of the purpose of practical work) was used as the typology for the study. The third typology was how practical work was conducted. This was based on Millar's model of developing and evaluating laboratory tasks (Millar et al., 2002). The typology took into consideration how teachers' views of science and learning (which in this context were the nature of practical work and its purpose and the practical and institutional context) influenced the objectives and design of the practical work task (what the teacher intended the students learn).

The definitions of practical work and its purpose, according to the literature reviewed in this study, were used as categories for analysing the interviews and the official documents. Practical and institutional context like class size among other things were developed from personal experience, common sense and the theoretical and conceptual 
framework of the study. However some categories -- for example 'to cater for different learners', which was the purpose of practical work, and 'discipline', which was the practical and institutional context, among other things -- emerged as the data was being analysed and were therefore used (Stake, 1995). Categories were given codes, as shown in appendix 1. The categories and codes were validated by a peer.

\section{Findings}

The interviews were read with one typology in mind and a summary sheet created for each typology per teacher (Hatch, 2002). The summary sheet contained only the main ideas of the respondent with no interpretation. This was done to attain primary descriptive validity (Maxwell, 1992). The summaries for each typology from the interviews were then coded using the categories developed. The official documents were also coded using the same coding systems used for the interviews. However, summaries were not created as there was not a large quantity of data. Teachers' ideas based on the codes were then tallied and frequency tables generated per typology, per research procedure. The frequency table enabled us to identify the main ideas from each typology based on the tallies. The results were also validated by the peer. The peer coded the data independently to check whether his results were the same as ours. There was one minor difference in terms of coding, which is whether teacher $\mathrm{M}$ conducted practical work in the explanation model or demonstration model. In the end we concluded with the use of both models. However this did not change the results significantly. The table below shows the summaries of the two teachers' ideas about the nature of practical work: its types, its purpose and how they conducted practical work.

Table 2 Summaries of the ideas about practical work

\begin{tabular}{|l|l|l|}
\hline & \multicolumn{1}{|c|}{ Teacher M } & \multicolumn{1}{|c|}{ Teacher B } \\
\hline Nature of practical work & $\begin{array}{l}\text { Investigation movement } \\
\text { Discovery movement }\end{array}$ & $\begin{array}{l}\text { Investigation movement } \\
\text { Process movement }\end{array}$ \\
\hline Types of practical work & $\begin{array}{l}\text { Illustration, investigation, observations } \\
\text { (demonstrations) }\end{array}$ & $\begin{array}{l}\text { Illustration, investigation, } \\
\text { (demonstrations) }\end{array}$ \\
\hline Purpose of practical work & $\begin{array}{l}\text { Procedural understanding, substantive } \\
\text { understanding, group work, enjoyment and motivation }\end{array}$ & $\begin{array}{l}\text { Substantive understanding, procedural } \\
\text { understanding, group work skills }\end{array}$ \\
\hline $\begin{array}{l}\text { How practical work was } \\
\text { conducted }\end{array}$ & $\begin{array}{l}\text { Explanation model } \\
\text { Demonstrations }\end{array}$ & Explanation model \\
\hline
\end{tabular}

\subsection{Discussion}

\subsubsection{Teachers' ideas about the nature of practical work}

Ideas about the nature of practical work, for teacher M, partially fit within the parameters of the investigation movement (Pekmez et al., 2005) because according to this teacher, practical work develops procedural understanding as well as enhances understanding of the content, as is evident from this explanation which the teacher gave of what practical work is:

\footnotetext{
Practical work as it says practical is something that they do it by themselves. Eh they use equipment which we call them apparatus and then to prove or to reinforce what they have learnt in class. So practical work I will take it that way. It is when they are using apparatus and equipments to reinforce what they have learnt during the lesson or sometimes you can use it. It depend which method you are either using deductive or inductive method. So you can start with the practical so that you can explain some concepts or you start with the concepts and use practical to explain it.
}

However, as there was no evidence of developing problem-solving skills, the ideas partially fit within the investigation movement. There was also some evidence of characteristics of the discovery movement, although not significantly so throughout the interview or in the documents. Teacher B's ideas about the nature of practical work best fit within the parameters of the process movement (Pekmez et al., 2005), because he stressed the doing of science while neglecting the content, as is evident from this statement:

According to my understanding practical work is that investigation that you engage learners into the investigation, practical something that they will do themselves, they are involved in conducting that kind of practical work and they do 
a particular research, not really a research they investigate but to investigate something they are given until they prove that particular thing. Right they see the results they observe what is happening, they collect or gather the apparatus or chemicals and each one of them touch. They have a feel of those particular results they were looking for.

There was also some evidence of characteristics of the investigation movement in the official documents. Even though the documents showed that substantive understanding and procedural understanding were developed, there was no attempt (as with teacher M) to develop problem-solving skills. Both teachers' understandings of the types of practical work varied from observations, illustration and investigation (Bennett, 2003). The types of practical work helped to understand the teachers' ideas about practical work because if the teacher indicated that he was conducting an investigation while performing a demonstration (like teacher B), it presented another perspective on the teacher's understanding of the nature of practical work.

\subsubsection{Teachers' ideas about the purpose of practical work}

Developing both general procedural and substantive understanding was the main purpose for both teachers $\mathrm{M}$ and $\mathrm{B}$. However procedural understanding was simply write-up.They also used practical work as a tool to develop group work skills. Teacher M also used practical work to develop his lesson, motivate learners and for enjoyment: "[T]he reasons most learners they love science because it is fun. Practical work it is fun. It is entertaining to them because if you teach and don't do practical work they don't enjoy it" (Teacher M interview, lines 53-54).

\subsubsection{How the Grade 10 teacher's ideas about the nature of practical work and its purpose shape how he or she conducts practical work}

Teacher M's ideas about the nature of practical work and its purpose best fit within the parameters of the investigation movement (Pekmez et al., 2005) even though there was no attempt to develop problem-solving skills. His understanding of the purpose of practical work was also largely based on developing procedural and substantive understanding. Hence the teacher should have conducted practical work within the performance model (Pekmez et al., 2005). However, how he conducted practical work best fit within the explanation model (Pekmez et al., 2005). How he conducted practical work does not fit within the performance model because the teacher did not focus on developing procedural understanding (Pekmez et al., 2005) and problem-solving skills, but focused on developing substantive understanding. Hence he used practical work as the teaching method to support the understanding of the content by learners. The write-up skills the teacher was aiming for concerned the laboratory reports, which would indicate to him that the learners understood the content better after producing well-written laboratory reports:

Hey ja, interpretation skills, observation, analysing because those skills you will get it back when they are doing their lab reports, because after they have done everything, they have to present it to you, explain it to you, what does it mean ...

Teacher B's ideas about the nature of practical work best fit within the parameters of the process movement (Pekmez et al., 2005), while his ideas about the purpose of practical work best fit within the parameters of the investigation movement (Pekmez et al., 2005). This teacher did not attempt to develop problem-solving skills. The teacher conducted practical work within the parameters of the explanation model (Pekmez et al., 2005) and used practical work to explain the content. Hence the teacher also conducted practical work to enhance learners' understanding. The teacher focused on substantive understanding, with procedural understanding only a part of the greater idea of enhancing the former. Hence, even though there was an attempt to develop procedural understanding in practice the emphasis was on enhancing the content, which means substantive understanding, as is evident from this statement: "[I]t assisted me in a way to make them understand the subject content more" (Teacher B interview, lines 142143).

Grade 10 teachers' ideas about the nature of practical work and its purpose do not necessarily shape how teachers conduct practical work. Teacher M's ideas are within the parameters of the investigation movement but he conducted practical work according to the explanation model. Teacher B's ideas are within the parameters of the process movement and the investigation movement but he conducted practical work according to the explanation model. The findings show another perspective to Millar et al's (2002) assertion that teachers' views of science and learning (in this context referring to what practical work is and its purpose) influence the design and objectives of a practical work task. Even though teachers' views influenced what they intended their students to learn, in practice that was not evident. Their 
views were in a framework different from the one within which they conducted the practical work tasks.

\subsection{Reasons for the difference in frameworks}

The following may be some of the reasons for the difference between the teachers' views about the nature of practical work and how they conducted practical work:

\subsubsection{Lack of procedural understanding.}

Both teachers demonstrated lack of procedural understanding in terms of classroom practice (Pekmez et al., 2005). Their instruction sheets were focused on what learners were expected to do and not on the outcomes (Ottander and Grelsson, 2006). This perpetuated a limited focus on developing procedural understanding. Because of this lack of focus on procedural understanding and its comprehension, the attempt to develop them became no more than the demonstration of using or seeing how apparatus is used. This may be the reason for the difference between the views teachers had about the nature of practical work and how they conducted practical work.

\subsubsection{Institutional and practical context.}

Each teacher had a class lasting for 35 minutes and sometimes the classes lasted 70 minutes. No much can be done within that limited time, which may also be why the teachers resorted to demonstrations. There are many topics in the Grade 10 syllabus and Perkins-Gough (2007: 93) indicates that "extensive lists of science topics in a given grade may discourage teachers from adopting more effective approaches to laboratory instruction". Having to cover many topics for the external examinations may have resulted in teachers resorting to demonstrations. Teacher $\mathrm{M}$ also indicated that disciplinary issues (Stoffels, 2005) also led him to conduct demonstrations. Teacher B indicated that not having a laboratory assistant stops him from conducting many practical work tasks. This sentiment was also echoed by teacher $\mathrm{M}$ who also indicated that he resorts to demonstrations because he had no lab assistant to clean up after him. The need to satisfy the portfolio requirement and continuous assessment (CASS) also caused the teachers to resort to demonstrations. Kapenda, Kandjeo-Marenga and Kasanda (2002) also indicated that Namibian teachers conducted demonstrations because they had large classes, and both teachers in this study had large classes. Resorting to demonstrations in turn resulted in the differentiation between the two teachers' views about the nature of practical work and how they conducted practical work.

\subsubsection{Lack of knowledge or skill to develop problem-solving skills and ensuring that tasks are learner-centred.}

Both teachers were in charge of the tasks and to a large extent they demonstrated the tasks. Their approach was teacher-centred (Stoffels, 2005). According to an inquiry approach the activities have to be student-centred (Kask and Rannikmäe, 2006) and to develop problem-solving skills (Department of Education, 2007). This deficiency in both teachers may also have resulted in the differences between their framework of views and how they conducted practical work.

\subsection{Implications for the curriculum}

Practical work should be conducted within the framework of scientific inquiry where learners perform investigations. However this study showed that teachers conducted what they call investigations which are not, however, entirely investigations. They did not attempt to develop problem-solving skills. Pekmez et al. (2005: 20) indicate that when "operating within a faulty framework, practical work could only succeed by accident rather than design". Indeed teachers had intentions of developing substantive and procedural understanding which is in line with what is scientific enquiry (Kask and Rannikmäe, 2006). However it was evident from this study that how the two teachers conducted practical work was not a reflection of their views about the nature and purpose of practical work. They thought that they were doing investigations while they were conducting practical work within the framework of the explanation model. They have these ideas but there was no evidence that they were putting them into practice. Teacher B's ideas were a bit more uncoordinated than teacher M's. His ideas were not as coherent as teacher M's, whose understanding of the nature of practical work and its purpose were within the same framework of the investigation movement. Neither of the teachers 
had their learners designing the practical work tasks, as required by the NCS. This then defeated the intentions of the DBE.

This brings into question the implementation of the curriculum. Rogan and Grayson (2003) indicate that South Africa is in danger of falling into the trap of designing visionary and educationally sound policies for the national curriculum without focusing on how to implement those policies. In their theory of curriculum implementation Rogan and Grayson (2003) identified three profiles: the profile of implementation, the profile of capacity to support innovation and the profile of support from outside agencies. Both the teachers in the profile of curriculum implementation are operating largely at level 2; they use demonstrations to promote a limited form of inquiry. At the profile of capacity to support innovation both the teachers satisfy this requirement; hence they operate at levels 3 to 4 . They are well-qualified, support from outside agencies is sufficient for the implementation of the new curriculum, and both teachers have adequately fitted laboratories, but the design of their professional development can be questioned. The above analysis shows that not much is done in terms of implementation. Rogan and Grayson (2003) indicate that this is usually the case for developing countries. This study has shown that there is cause for concern about the issue of curriculum implementation with regard to practical work.

\subsection{What can be done?}

The study has shown that teacher' ideas about what entails practical work and its purpose do not necessarily ensure that they conduct practical work according to their ideas. What became evident in this study was that teachers were doing what they thought was developing procedural understanding, although they were not. This means they do not understand what procedural understanding is. This finding was also reported by Kapenda et al. (2002). Pekmez et al. (2005) found that there is need "... to develop a deeper understanding of the procedural knowledge base amongst a significant proportion of science teachers". This assertion is also reported by Bennett (2003).

Kask and Rannikmäe (2006) also indicate that the collaboration within schools on the best practices in practical work should be taken into consideration. Teachers are encouraged not to become derailed by the contextual factors but to stand back to take a look at themselves and seek advice where necessary. Rogan and Grayson (2003: 1200) indicate that "changing teaching and leaning practices should be viewed as a change of culture rather than merely a technical matter". Hence teachers themselves have the challenge of accepting the new approach, allowing it to become part of them and then practising it. Rogan and Grayson (2003) further point out that if teachers attend workshops and fail to implement what they have learnt there will be no change.

The study by Kask and Rannikmäe (2006) has shown that intervention is very important in teachers' evolution towards inquiry approaches. Bennett (2003: 96) also points out that "the messages emerging from current thinking on practical work are that the emphasis needs to shift from doing to discussion". So in future much more time needs to be devoted to engaging teachers in discussions on how to put the Department of Education learning area and assessment guideline policy on science inquiry into practice. Hence intervention through cluster meetings is recommended.

However, Rogan and Grayson (2003) indicate that the reason for the failure of well-designed and well-intentioned curricula in developing countries is the lack of clearly thought-out implementation strategies. It is necessary to engage teachers in meaningful, planned discussion on scientific inquiry which would encompass both procedural and substantive understanding. Cluster meetings should be organised to enable teachers eventually to operate at level 4 for all the profiles on theory of implementation (Rogan and Grayson, 2003). This could be achieved by implementing the policies of practical work in manageable steps wherein teachers are scaffolded (Rogan and Grayson, 2003) into how to design and conduct practical work. Rogan and Grayson (2003: 1197) further indicate that "to build capacity without linking it to implementation is fruitless". Cluster leaders or facilitators should take into consideration that practical work tasks reflect the ideas discussed in the previous meetings and assist teachers accordingly. Ultimately the ideal situation should be to establish communities that "develop shared values and goals regarding educational practice and a commitment to put these into practice" (Rogan and Grayson, 2003: 1194).

\section{Conclusion}

The study showed that there is an attempt to conduct practical work, even though it is happening within a faulty framework. Stoffels (2005) indicated that teachers need a boost in confidence for them to operate competently. The study has shown this need. How well the results of the study best represent the majority of science teachers is debatable, but the findings can stimulate thought around the understandings of practical work and its implementation. 
The study has shown a need to link the understandings of practical work and of teacher practice if the inquiry approach is to be a success. Therefore the current methods used to inform physical science teachers on how to conduct practical work are called into question.

\section{References}

Bennett, J. (2003). Teaching and Learning Science. Continuum. London. 73-98.

Department of Education. (2007). National Curriculum Statement Grades 10-12 Subject Assessment Guidelines Physical Sciences. Pretoria: Department of Education.

Hatch, J.A. (2002). Doing qualitative research in educational settings. SUNY. New York.

Hitchcock, G. and Hughes, D. (1995) Research and the teacher: A qualitative Introduction to School-based Research. Routledge. London and New York. 316-329.

Hodson, D. (1990). A critical look at practical work in school science. School Science Review. 70 (256), 33-40.

Kapenda, H.M., Kandjeo-Marenga, H.U. and Kasanda, C.D. (2002). Characteristics of practical work in Science Classrooms in Namibia. Research in Science and Technological Education. 20(1), 53-65.

Kask, K. and Rannikmäe, M. (2006). Estonian Teachers' Readiness to Promote Inquiry Skills Among Students. Journal of Baltic Science Education. 1(9), 5-16.

Maxwell, J.A. (1992). Understanding and validity in qualitative research. In Harvard Educational Review, 62(3). 279-300.

McMillan, J. H. and Schumacher, S. (2006). Research in Education Evidence-based inquiry (6 $6^{\text {th }}$ ed). Pearson Education. Boston.

Millar, R., Le Maréchal, F. and Tiberghien. A. (2002). Varieties of labwork: a way of profiling Labwork tasks, In Psillos, D. and Niedderer, H. (Eds). Teaching and Learning in the Science Laboratory. Dordrecht: Kluwer, 9-20.

Ottander, C. and Grelsson, G. (2006). Laboratory work: the teachers' perspective. Journal of Biology Teaching. 40 (3), 113-118.

Pekmez, E. S., Johnson, P. and Gott, R. (2005) Teachers' understanding of the nature and purpose of practical work. Research in Science \& Technological Education. 23(1), 3-23.

Perkins-Gough, D. (2007). The Status of the Science Lab, special report. Educational leadership. 93-94.

Rogan, J.M. and Grayson, D.J. (2003). Towards a theory of curriculum implementation with particular reference to science education in developing countries. International Journal of Science Education. 25(10), 1171-1204.

Stake, R.E. (1995). The art of case study research. SAGE publications. USA.

Stoffels, N.T. (2005). "There is a worksheet to be followed": A case study of a science teacher's use of learning support texts for practical work. African Journal of Research in SMT Education. 9(2), 147-157. 